\title{
A numerical study of indoor air quality in a ventilated room using different strategies of ventilation
}

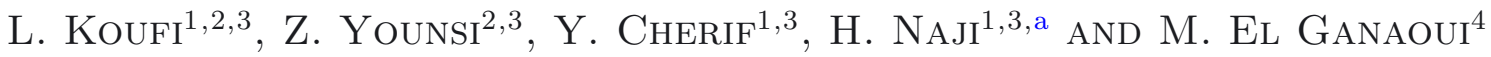 \\ 1 Univ. Artois, EA 4515, Laboratoire de Génie Civil et géo-Environnement (LGCgE, EA 4515), 62400 Béthune, France \\ 2 FUPL, Haute Études d'Ingénieur (HEI), 59000 Lille, France \\ 3 Université Lille Nord de France, LGCgE, 59000 Lille, France \\ 4 Université de Lorraine, LERMAB, Institut Universitaire de Technologie de Longwy, 54400 Cosnes et Romain, France
}

Received 29 January 2016, Accepted 17 August 2016

\begin{abstract}
This study aimed to numerically investigate the air flow and contaminant dispersion in a ventilated room. The URANS equations supplemented with energy and concentration equations are solved using the scStream code. We are targeting primarily the ventilation effectiveness $\left(\varepsilon_{c}\right)$ and the index of indoor air quality $\left(I_{\mathrm{IAQ}}\right)$. Different displacement and mixing ventilation modes are investigated in isothermal conditions. The ventilation flow rate is $50 \mathrm{~m}^{3} \cdot \mathrm{h}^{-1}$ Here, our ultimate aim is to suggest an effective ventilation that can ensure a good indoor air quality. The $R N G k-\varepsilon$ model was adopted to handle the turbulence. CFD simulations were systematically checked, whenever possible, through available results. The simulation results indicate that the ventilation effectiveness to remove a contaminant and the index of indoor air quality are substantially influenced by the ventilation mode and the location of inlet and outlet air. From this study, it appears that the air flow and contaminant dispersion in a ventilated room can be typically predicted or evaluated by computer simulations.
\end{abstract}

Key words: CFD simulation / displacement ventilation / mixing ventilation / indoor air quality / ventilation efficiency / turbulence

\section{Introduction}

A healthy indoor environment is of paramount importance for the comfort and health of human beings. Indeed, today, users spend more time inside the premises (homes, schools, offices, transports, stores, etc.) [1]. Many pollutants from a variety of sources may be present in this environment and sometimes at higher concentrations than outside. For a question of energy saving, the exchanges between the outside and inside buildings were greatly reduced what could drive a containment situation thus leading to deterioration in air quality.

The ventilation process might be defined as an intentional controlled introduction of outdoor air into spaces. It is the primary mechanism for removing contaminants from within buildings. Thereby, the ventilation is now considered as a promising solution to ensure a good quality of indoor air. Its role is to renew sufficiently stale air by fresh air unpolluted and evacuate pollutants of the occupation zones. However, this technique can result in significant energy costs. Indeed, the introduction of fresh

\footnotetext{
a Corresponding author:

hassane.naji@univ-artois.fr
}

air causes important temperature gradients that affect the thermal comfort of occupants. These temperature gradients can be negative or positive depending on the climate. For this, different ventilation strategies have been adopted to ensure a good quality of indoor air firstly, and limit energy losses on the other hand.

Note that in a ventilated room, two physical phenomena may occur: natural convection driven by buoyancy forces of heat in the presence of sources of contamination and forced convection drained by external forces in the attendance of mechanical ventilation. For ventilation of a room, two mechanical ventilation modes are widely used. These modes are in function of the fresh air intake speed. These are the mixing ventilation where the air fresh is blown at high speed (turbulent air jets) and the displacement ventilation where air is supplied at low speed [2].

Several studies have been conducted to deepen understanding of the behavior of air flow and distribution of heat and pollutants inside the ventilated rooms. Also, numerical and experimental analyses of mixed convection in air-filled open cavities were performed. Below, we briefly describe some work on the topic discussed here. Chung and Hsu [3] conducted a numerical and experimental 


\section{Nomenclature}

\begin{tabular}{|c|c|c|c|}
\hline$C$ & Chemical species' concentration (ppm) & $\dot{Q}$ & Ventilation rate $\left(\mathrm{m}^{3} \cdot \mathrm{h}^{-1}\right)$ \\
\hline $\bar{C}$ & Average concentration (ppm) & $S h$ & Local Sherwood number $\left(S h=-(\partial C / \partial x) \Delta C^{-1}\right)$ \\
\hline$C_{0}$ & Reference concentration (ppm) & $\overline{S h}$ & Averag Sherwood number $\left(\overline{S h}=\int_{0}^{L} S h \mathrm{~d} z\right)$ \\
\hline$C_{\text {in }}$ & Chemical species' concentration at inlet (ppm) & $t$ & Time (s) \\
\hline$C_{\text {out }}$ & Chemical species' concentration (ppm) & $T$ & Temperature $(\mathrm{K})$ \\
\hline$C_{\mathrm{th}}$ & Threshold concentration (ppm) & $T_{0}$ & Temperature reference $(\mathrm{K})$ \\
\hline$C_{p}$ & Specific heat $\left(\mathrm{J} \cdot \mathrm{Kg}^{-1} \cdot \mathrm{K}^{-1}\right)$ & $u_{i}$ & Velocity components $\left(\mathrm{m} . \mathrm{s}^{-1}\right)$ \\
\hline$D$ & Diffusion coefficient of chemical species $\left(\mathrm{m}^{2} \cdot \mathrm{s}^{-1}\right)$ & $U_{\text {in }}$ & Velocity inlet $\left(\mathrm{m} \cdot \mathrm{s}^{-1}\right)$ \\
\hline$I_{\mathrm{IAQ}}$ & Indoor air quality index & $x_{i}$ & Coordinates $(\mathrm{m})$ \\
\hline$G$ & Gravity acceleration $\left(\mathrm{m} . \mathrm{s}^{-2}\right)$ & & Greeks symbols \\
\hline$K$ & Turbulent kinetic energy $\left(\mathrm{m}^{2} \cdot \mathrm{s}^{-1}\right)$ & & \\
\hline$L$ & Characteristic length $(\mathrm{m})$ & $\alpha$ & Thermal diffusivity $\left(\mathrm{m}^{2} \cdot \mathrm{s}^{-1}\right)$ \\
\hline$L e$ & Lewis number $\left(L e=\alpha / D_{A B}\right)$ & $\beta_{T}$ & Thermal expansion coefficient $\left(\beta_{T}=T_{0}^{-1}, K^{-1}\right)$ \\
\hline$n$ & Normal direction & $\beta_{c}$ & Concentration expansion coefficient $\left(\beta_{c}=C_{0}^{-1}\right)$ \\
\hline$N$ & Buoyancy ratio $\left(N=\beta_{c} \Delta C / \beta_{T} \Delta T\right)$ & $\varepsilon$ & Turbulent energy dissipation $\left(\mathrm{m}^{2} \cdot \mathrm{s}^{-3}\right)$ \\
\hline$N u$ & Local Nusselt number $\left(N u=-(\partial T / \partial x) \Delta T^{-1}\right)$ & $\varepsilon_{c}$ & Ventilation effectiveness coefficient \\
\hline$\overline{N u}$ & Average Nusselt number $\left(\overline{N u}=\int_{0}^{L} N u \mathrm{~d} z\right)$ & $\lambda$ & Thermal conductivity $\left(\mathrm{W} \cdot \mathrm{m}^{-1} \cdot \mathrm{K}^{-1}\right)$ \\
\hline$p$ & Fluid pressure $(\mathrm{Pa})$ & $\mu$ & Dynamic viscosity $\left(\mathrm{kg} \cdot \mathrm{m}^{-1} \cdot \mathrm{s}^{-1}\right)$ \\
\hline $\operatorname{Pr}$ & Prandtl number $(\operatorname{Pr}=\nu / \alpha)$ & $\rho$ & Density of the mixture $\left(\mathrm{kg} . \mathrm{m}^{-3}\right)$ \\
\hline
\end{tabular}

study of the influence of ventilation on the distribution of contaminants inside isothermal three-dimensional chamber in turbulent and transient flow regime. The authors found that the ventilation efficiency is on function of the location of diffusers supply and exhaust. Bjorn and Nielsen [4] conducted a numerical and experimental study of the influence of the expiry of the humanbeing on the fields of flow, distribution of contaminants and exposure to pollutants in chamber-test equipped with different scenarios of displacement ventilation. The authors have shown that the effect of the exhalation flow is no acute in most normal ventilation applications. However, the movement of people inside is not appropriate to maintain a minimum concentration in some areas such as smoking areas, hospitals or certain industrial zones. Moureh and Flick [5] performed a numerical and experimental study of an air flow in an open three-dimensional rectangular cavity in turbulent and steady regime. It has been found that the configuration "central inlet section" is formed the stagnant zones at the bottom of the cavity. These prevent the lateral flow separation reflecting low efficiency of ventilation. Also, it has been observed that the configuration "side inlet section" maintains the uniformity and the homogeneity throughout the enclosure and so improves the efficiency of ventilation to remove heat and mass gradients. Tian et al. [6] studied a numerical analysis to simulate the dispersion of contaminants (particles) and the concentration distribution within a three-dimensional local in turbulent and transient flow. They compared the dynamics and mass fields obtained by three turbulence models with measurements made by Posner et al. [7]. They found that all models considered give favorable predictions. They also found that the LES model offers best results and the model is better than the standard $k-\varepsilon$ model. Niachou et al. [8] performed an experimental study of the performance of natural and hybrid ventilation systems in three apartments characterized by a different geometry oriented in a distinct way. They realized a measurement campaign during a summer period. The purpose of the study was to show the impact of the urban environment on the effectiveness of ventilation systems. Tracer gases were applied during the experimental procedures with one gas $\left(\mathrm{N}_{2} \mathrm{O}\right)$, and then two gases $\left(\mathrm{N}_{2} \mathrm{O}\right.$ and $\left.\mathrm{SF}_{6}\right)$. They found that when the wind speed is low, the significant rate of air exchange can be achieved by natural ventilation, particularly in the case of transversal ventilation. Furthermore, they showed that the hybrid ventilation has a slight advantage over the simple natural ventilation face or in calm conditions. Liu Di et al. [9] conducted a numerical study on the indoor air quality inside a cubic cavity ventilated in turbulent and steady regime. The cavity is equipped with a mechanical ventilation system with a heat exchanger. The ventilation device has three apertures of the same dimensions: an air supply, an air outlet and an air recirculation. They showed that the increase in the Reynolds number is effective to reduce the average concentration levels. Tung et al. [10] studied experimentally the dispersion of pollutants in a humid three-dimensional room (bathroom). The authors examined the effectiveness of the ventilation to eliminate unpleasant odors using the tracer gas method. They found that the double flow mechanical ventilation is much better than the simple flow mechanical ventilation. Liu Di et al. [11] realized a numerical study of heat and mass transfer by mixed convection in an open cubic cavity in turbulent regime. It has been found that the reduction of contaminant levels can be achieved either by increasing the fresh air or recirculation ratio of intensity or the supply air flow, or by decreasing the power of the heating source. Jurelionis et al. [12] performed a numerical and experimental study of the impact of ventilation on the behavior of the aerosol particles $(\mathrm{NaCl})$ in a room 
equipped with a controlled mechanical ventilation double flow system. They found that the mixing ventilation have a high air renewal rate $\tau(\geq 3)$ with an air contribution at one-way prevents the $\mathrm{NaCl}$ particles to move to the opposite side of the room. Also, they found that displacement ventilation is ineffective, which resulted in an age of air $16.7 \mathrm{~s}$ on average when $\tau$. It should be noted that this value is relatively high with respect to the mixing ventilation (9.9 s). Rodriguez et al. [13] have studied numerically and experimentally the heat transfer by mixed convection in a cubic cavity filled with air. They found differences of $2 \%$ between the measured and computed temperatures when thermal Rayleigh number $R a_{T}=2.7 \times 10^{8}$ $\left(R a_{T}=\rho g \beta \Delta T H^{3} /(\alpha \mu)\right)$ and $3 \%$ when $R a_{T}=4.5 \times 10^{8}$. They also found that convection coefficients predicted are closer to those obtained experimentally for a Reynolds number of $31466\left(R e=\rho U_{i n} D_{h} / \mu\right)$. For this value of $R e$, the differences are $0.8 \%$ for $R a_{T}=2.7 \times 10^{8}$ and $0.3 \%$ for $R a_{T}=4.5 \times 10^{8}$.

Since the ventilation effectiveness is typically used in building, we conducted a numerical study to predict the aero-solutal behavior inside a three-dimensional ventilated room. To achieve this, the unsteady Reynolds averaged Navier-Stokes (URANS) equations are solved via the scSTREAM Code To handle the turbulence, the $R N G k-\varepsilon$ model [14] is used. The main aim here is to test different mixing and displacement ventilation strategies in order to propose an effective strategy that takes less time to evacuate the contaminant and to ensure a good indoor air quality.

The rest of the paper is organized as follows. Section 2 describes the physical model and presents the governing equations supplemented by specific boundary conditions. Further, key parameters of this study are presented in Section 3. Section 4 deals with a brief description of the numerical approach while emphasizing its validation. A thorough discussion of simulation results takes place in Section 5. Lastly, we conclude in Section 6 while targeting the salient results.

\section{Problem statement and mathematical model}

\subsection{Physical model of the ventilated room}

The studied physical system is depicted in Figure 1. It consists of a ventilated room of dimensions $4 \times 3 \times 2.5 \mathrm{~m}^{3}$ filled with an air- $\mathrm{CO}_{2}$ mixture. It is provided with two openings for the supply of fresh air and the evacuation of contaminated air. The ventilation rate was $50 \mathrm{~m}^{3} \cdot \mathrm{h}^{-1}$. The walls are adiabatic and impermeable.

Figure 2 illustrates the ventilation scenarios studied in this work. Recall that there are two mixing ventilation systems and two displacement ventilation systems. In the case of the mixing ventilation, the supply and exhaust are provided either at the side walls (Fig. 2a) or at the ceiling level (Fig. 2b). In the case of displacement ventilation, the supply and exhaust are either at a single side

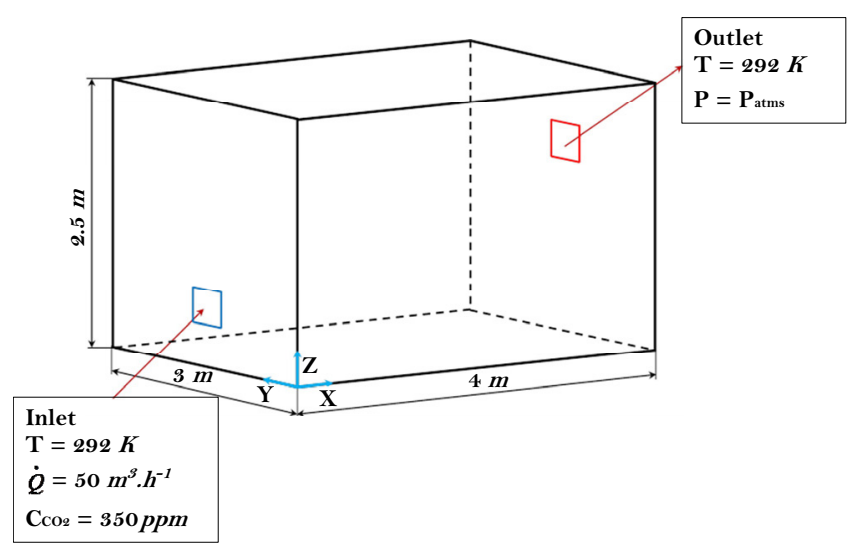

Fig. 1. Physical model of the ventilated room.

wall (Fig. 2c) or at the ceiling level (Fig. 2d). Air outlet vents are circular. It should be noted that air inlets are rectangular for the case $\mathrm{d}$ and circular for cases a and $\mathrm{c}$. For the case b, we considered a square cassette. The angle of incidence of the jet is $30^{\circ}$ for the case a, $0^{\circ}$ for the case $\mathrm{b},-60^{\circ}$ for case $\mathrm{c}$, and $90^{\circ}$ for to the case $\mathrm{d}$.

\subsection{Mathematical model}

The conservation equations are simplified by adopting the following conjectures: the fluid is Newtonian and incompressible, the flow is turbulent and unsteady, viscous dissipation and the work of the pressure forces and the transfer by radiation are negligible. Likewise, we have considered that the Boussinesq approximation remains valid within the frame of our study. Note that the level of concentration of $\mathrm{CO}_{2}$ is considered low (the amount of $\mathrm{CO}_{2}$ is much lower than air $(0.02 \%))$. Under these assumptions, the averaged equations governing the aero-thermosolutal flow are the following:

$$
\begin{gathered}
\frac{\partial \rho}{\partial t}+\nabla \cdot(\rho U)=0 \\
\frac{\partial(\rho \vec{U})}{\partial t}+\nabla \cdot(\rho \vec{U} \otimes \vec{U})=-\nabla p+\nabla \cdot\left(\mu \nabla \vec{U}-\overrightarrow{u_{i}^{\prime} u_{j}^{\prime}}\right) \\
+\rho\left[g \beta_{T}\left(T-T_{0}\right)+g \beta_{C}\left(C-C_{0}\right)\right] \overrightarrow{e_{3}} \\
\frac{\partial\left(\rho C_{p} T\right)}{\partial t}+\nabla \cdot\left(\rho C_{p} T \vec{U}\right)=\nabla\left(\lambda \nabla T-\rho C_{p} \overline{u_{i}^{\prime} T^{\prime}}\right) \\
\frac{\partial(\rho C)}{\partial t}+\nabla \cdot(\rho C \vec{U})=\nabla\left(\rho D \nabla C-\rho \overline{u_{i}^{\prime} C^{\prime}}\right)
\end{gathered}
$$

where $\rho \overline{u_{i}^{\prime} u_{j}^{\prime}}, \rho \overline{u_{i}^{\prime} T^{\prime}}$ and $\rho \overline{u_{i}^{\prime} C^{\prime}}$ are the average Reynolds stresses, turbulent heat and mass fluxes, respectively, which are modeled as follows:

$$
\begin{aligned}
& \rho \overline{u_{i}^{\prime} u_{j}^{\prime}}=-\mu_{t} S_{i j}+(2 / 3) \rho k \delta_{i j} \\
& \rho \overline{u_{i}^{\prime} T^{\prime}}=-\alpha_{t} \nabla T \\
& \rho \overline{u_{i}^{\prime} C^{\prime}}=-D_{t} \nabla C
\end{aligned}
$$

where $k=\overline{u_{i}^{\prime} u_{i}^{\prime}} / 2$ is the turbulent kinetic energy, $\delta_{i j}$ is the Kronecker tensor, $\mu_{t}$ is the eddy viscosity, $\alpha_{t}$ and 


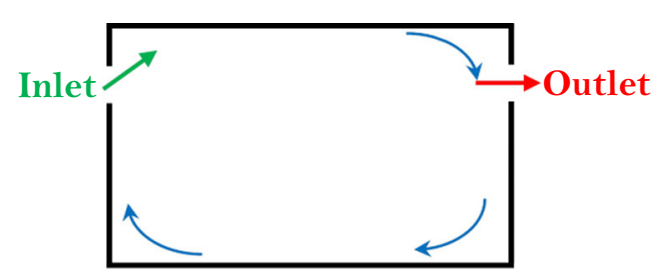

(a)

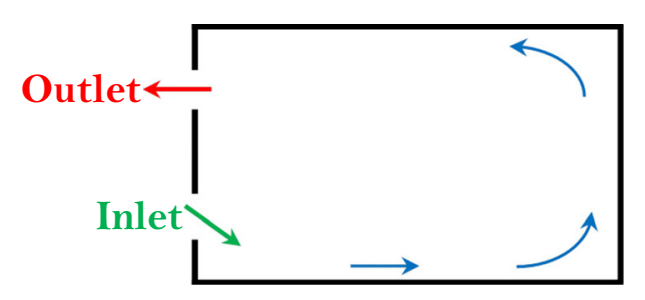

(c)

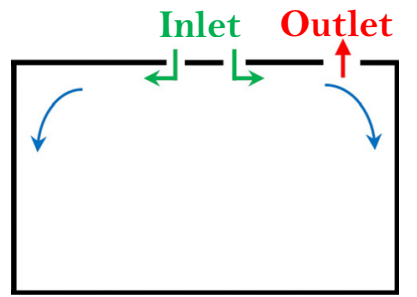

(b)

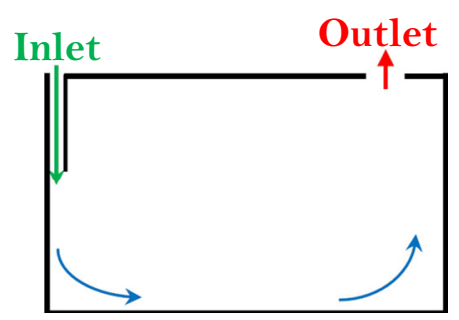

(d)

Fig. 2. Ventilation scenarios; (a) Mixing ventilation (wall supply and extract), (b) Mixing ventilation (ceiling supply and extract), (c) Displacement ventilation (wall supply and extract), (d) Impinging jet ventilation (ceiling supply and extract).

Table 1. model constants of the $R N G k-\varepsilon$ model.

\begin{tabular}{cccccc}
\hline$\sigma_{k}$ & $\sigma_{\varepsilon}$ & $C_{1}$ & $C_{2}$ & $C_{3}$ & $C_{\mu}$ \\
\hline 0.719 & 0.719 & $C_{1}(\eta)$ & 1.68 & 0.0 & 0.085 \\
\hline
\end{tabular}

$D_{t}$ are the turbulent thermal diffusivity and turbulent mass diffusivity, respectively. The eddy viscosity $\mu_{t}$ is estimated by:

$$
\mu_{t}=C_{\mu} \rho k^{2} / \varepsilon
$$

The closure of the system (1)-(4) is achieved via the transport equations of turbulent kinetic energy $(k)$ and its dissipation rate $(\varepsilon)$. These can be written as follows:

$\frac{\partial(\rho k)}{\partial t}+\nabla \cdot(\rho k \vec{U})=\nabla\left[\left(\mu+\left(\mu_{t} / \sigma_{k}\right)\right) \nabla k\right]+G_{s}+G_{t}+\rho \varepsilon$

$$
\begin{aligned}
& \frac{\partial(\rho \varepsilon)}{\partial t}+\nabla \cdot(\rho \varepsilon \vec{U})=\nabla\left[\left(\mu+\left(\mu_{t} / \sigma_{\varepsilon}\right)\right) \nabla \varepsilon\right] \\
& \quad+C_{1}\left(G_{s}+G_{t}\right)\left(1+C_{3} R_{f}\right)(\varepsilon / k)-C_{2}\left(\rho \varepsilon^{2} / k\right)
\end{aligned}
$$

with $G_{s}=\mu_{t} S_{i j} \nabla \cdot \vec{U}, G_{t}=g_{i} \beta_{T}\left(\mu_{t} / P r_{t}\right) \nabla T+$ $g_{i} \beta_{C}\left(\mu_{t} / S c_{t}\right) \nabla C, \quad R_{f}=-G_{t} /\left(G_{t}+G_{s}\right), \quad S_{i j}=$ $\left(\partial \overline{u_{i}} / \partial x_{j}\right)+\left(\partial \overline{u_{j}} / \partial x_{i}\right)$, and $\sigma_{k}, \sigma_{\varepsilon}, C_{1}, C_{2}, C_{3}, C_{\mu}$ are the model constants whose values are given in Table 1 , with $C_{1}(\eta)=1.42-\left(\eta(1-\eta / 4.38) /\left(1+0.012 \eta^{3}\right)\right), \eta=k S / \varepsilon$ and $S=\left(S_{i j} S_{i j}\right)^{1 / 2}$.

\subsection{Boundary conditions}

The considered system of Equations (1)-(10) is completed with suitable boundary conditions (BCs). These are: $U=0$ on all solid surfaces, $U=U_{\text {in }}$ at the air inlet, $\partial U / \partial n=0$ at the air outlet where $n$ is the unit vector normal to the flow direction. As for thermal BCs, the room is supposed isotherm at $292 \mathrm{~K}$ and its walls are adiabatic. For the $\mathrm{CO}_{2}$, we assumed that its concentration is $2000 \mathrm{ppm}$ at $t=0$, while the air enters at a concentration of $350 \mathrm{ppm}$. At the outlet, we set $\partial C / \partial n=0$. Regarding the turbulent quantities, their values are those advocated by Henkes et al. [15].

It is noteworthy that the choice of rate $\left(50 \mathrm{~m}^{3} \cdot \mathrm{h}^{-1}\right)$ is due to the French regulations which requires a minimum ventilation rate of $35 \mathrm{~m}^{3} \cdot \mathrm{h}^{-1}$. In addition, the velocity has been used as parameter to size the air inlet. From the relationship between the flow rate, inlet velocity and the inlet section, we deduce the later quantity (air inlet section), and hence the Reynolds number $\left(R e=\left(\rho U_{i n} D_{h}\right) / \mu\right)$ for each scenario, $D_{h}$ being the hydraulic diameter. Thereby, the Reynolds numbers obtained for each scenario are $R e_{a}=7.5 \times 10^{3}, R e_{b}=3 \times 10^{3}, R e_{c}=7.5 \times 10^{3}$ and $R e_{d}=5 \times 10^{3}$, respectively.

\section{Characteristic parameters}

\subsection{Ventilation effectiveness to remove contaminant}

Awbi [2] defines the efficiency of a ventilation scenario $\left(\varepsilon_{c}\right)$ to remove a contaminant element as the ratio of the concentration difference between the extracted air $\left(C_{\text {out }}\right)$ and the blown air $\left(C_{\text {in }}\right)$ by the difference between the average concentration of the interior air $(\bar{C})$ and the concentration of the blown air. This quantity allows assessing the ability of a ventilation system to remove pollutants in a ventilated domain.

$$
\varepsilon_{c}=\frac{C_{\mathrm{out}}-C_{\mathrm{in}}}{\bar{C}-C_{\mathrm{in}}}
$$


Note that a value greater than unity $\varepsilon_{C}$ translates effective ventilation.

\subsection{Index of indoor air quality}

The index of indoor air quality $\left(I_{\mathrm{IAQ}}\right)$ is defined as the ratio of the difference between the average concentration in the interior $(\bar{C})$ and the concentration of extracted air $\left(C_{\text {out }}\right)$, and the difference of the concentration "threshold" $\left(C_{\mathrm{Th}}\right)$ and $\left(C_{\text {out }}\right)$. It is used to assess the quality of indoor air with respect to a pollutant. It is defined by the relation:

$$
I_{\mathrm{IAQ}}=\frac{\bar{C}-C_{\text {out }}}{C_{\mathrm{Th}}-C_{\text {out }}}
$$

Note that when $I_{\mathrm{IAQ}}$ less than unity, the quality of indoor air is good.

\section{Numerical procedure}

\subsection{Discretization}

The computational analysis is performed using the general purpose finite-volume CFD code scStream. A quadratic structured mesh is used with a coefficient geometric expansion of 1.05. The terms of advection and diffusion are discretized using first-order upwind scheme. The Simplec algorithm [16] was used for the pressurevelocity coupling. The resolution of the resulting algebraic system is achieved using multiple-iteration constrained conjugate gradient (MICCG).

Before the targeted simulations, we have checked the independence of the mesh with respect to results. For this, we built four mesh grids with a time step of $0.01 \mathrm{~s}$ $(21 \times 26 \times 31,41 \times 46 \times 51,61 \times 66 \times 71$ and $81 \times 86 \times 91)$. The obtained results indicated that the last two grids provide similar velocity and concentration profiles plotted at different points of the area. Therefore, we selected the grid $61 \times 66 \times 71$ for all calculations presented in this study. Similarly, we examined the temporal evolution of velocity and concentration considering different time steps (0.5, $0.1,0.05$ and $0.01 \mathrm{~s})$. It was found that a time step less than $0.05 \mathrm{~s}$ gives satisfactory results. Normalized residuals required for convergence has been $10^{-8}$ for the energy, and $10^{-5}$ for the remaining equations that correspond to $1 \%$ of the default tolerance settings of scStream.

\subsection{Validation and verification}

It is now accepted that a numerical code requires verification and validation of the results with the literature data. To check and validate our approach, two different problems were considered: (1) heat and mass transfer within a closed square cavity in laminar and steady regime, and (2) a ventilated room in isothermal conditions under turbulent and transitional flow regime.

The first problem was carried out by Béghein et al. [17 and Xaman et al. [18]. The cavity is differentially heated

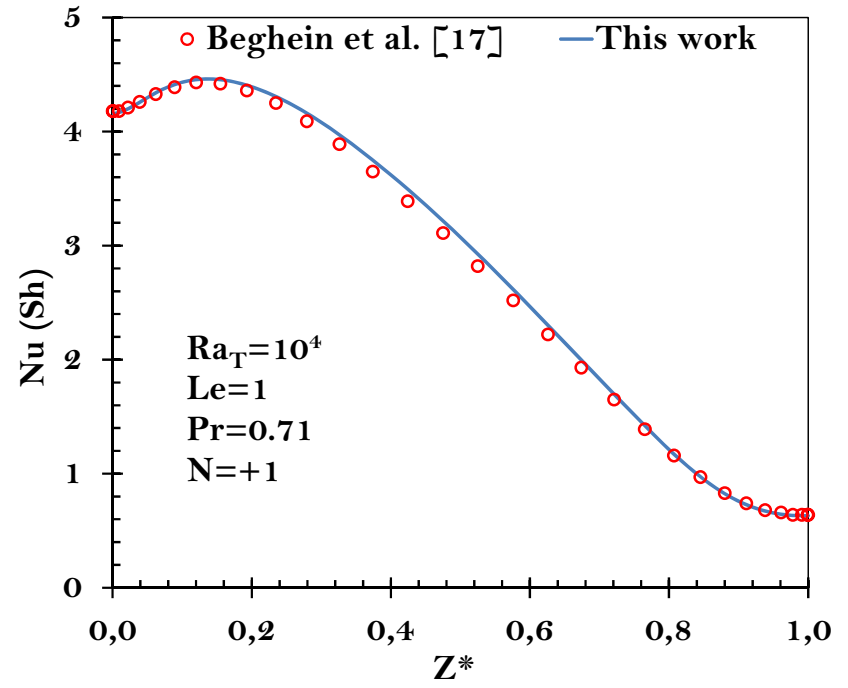

Fig. 3. $N u$ and $S h$ vs. $Z^{*}$ at $X^{*}=0$; comparison with Reference [17].

Table 2. Comparison of $\overline{N u}$ for $R a_{T}=10^{7} \operatorname{Pr}=0.71$, and $L e=1$.

\begin{tabular}{cccc}
\hline \multicolumn{3}{c}{$\overline{N u}(\cong \overline{S h})$} \\
\hline$N$ & This work & Reference $[18]$ & Reference $[17]$ \\
\hline-0.01 & 13.38 & 16.6 & 16.4 \\
-0.10 & 16.01 & 15.9 & 16.0 \\
-0.20 & 15.32 & 15.4 & 15.5 \\
-0.50 & 13.55 & 13.6 & 13.6 \\
-0.80 & 10.61 & 10.6 & 10.6 \\
-0.90 & 8.79 & 8.8 & 8.8 \\
-1.50 & 13.55 & 13.6 & 13.6 \\
-5.00 & 23.67 & 23.7 & 23.7 \\
\hline
\end{tabular}

with a concentration gradient between the vertical walls. The horizontal walls are adiabatic and impermeable. To perform this comparison, the following dimensionless parameters were used: Prandtl number $(\operatorname{Pr}=0.71)$, thermal Rayleigh number $\left(R a_{T}=10^{4}\right.$ and $\left.10^{7}\right)$, Lewis number $(L e=1)$ and various buoyancy reports $(N=$ $-5,-1.5,-0.9,-0.8,-0.5,-0.2,-0.1,-0.01,1)$. The comparison results are shown in Figure 3 for the local $N u$ and $S h$ Likewise, Table 2 gathers comparisons for $\overline{N u}$ and $\overline{S h}$. We see that the results are in good agreement.

The second problem was studied by Chung and Hsu [3]. It concerns a ventilated three-dimensional room filled with an air- $\mathrm{CO}_{2}$ mixture. In the initial state, the concentration of $\mathrm{CO}_{2}$ is at $2000 \mathrm{ppm}$ and the mixture temperature is at $300 \mathrm{~K}$. Fresh air is introduced at a temperature of $300 \mathrm{~K}$ and at a concentration of $350 \mathrm{ppm}$. The ventilation flow rate is $391.7 \mathrm{~m}^{3} \cdot \mathrm{h}^{-1}$. The comparisons achieved are shown in Figure 4 for the velocity at different measuring points when the steady state is reached, and in Figure 5 for the temporal evolution of the concentration at the outlet. It is noted that the numerical predictions corroborate the experimental data of [3]. 


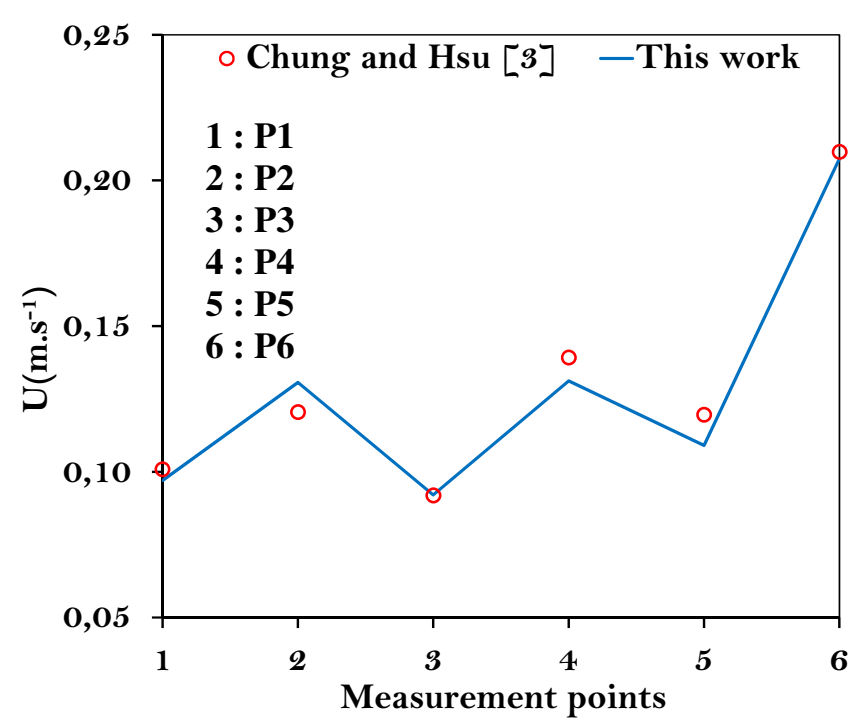

Fig. 4. Velocity at various measuring points; comparison with Reference [3].

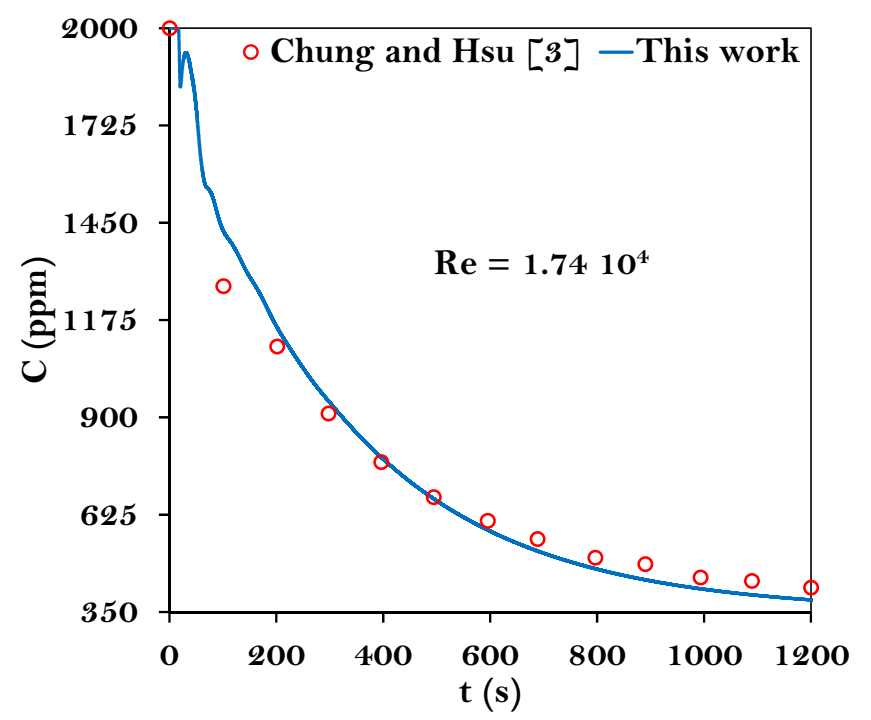

Fig. 5. Temporal evolution of the concentration at outlet; comparison with [3].

In the light of these comparisons, it can be concluded that the numerical approach, for the case of this study, provides satisfactory results.

\section{Results and discussions}

In the following, we present the results of ventilation systems presented in Figure 2 for each of the scenarios, iso-concentrations and the temporal evolution of the concentration of $\mathrm{CO}_{2}$ are presented for different measurement points. The coordinates of these points are gathered in Table 3.

Figure 6 illustrates the temporal evolution of isoconcentrations plotted at $Y=0.5,1.5$ and $2.5 \mathrm{~m}$. It is seen that, in the vicinity of the air inlet, the concentration is low and is about $350 \mathrm{ppm}$ and that, for the four scenarios. This is due to the rapid dilution of the mixture due to the fresh air which sweeps these zones very quickly. The rest of the area exhibits an almost perfect homogeneity. Also, concentrations decrease gradually over time. It should be noted that the scenarios b, c and d present poorly ventilated areas after $70 \mathrm{~min}$. These areas disappear after $100 \mathrm{~min}$.

Figure 7 shows the temporal evolution of the concentration of $\mathrm{CO}_{2}$ of each of the measuring points of the four scenarios. It is found that, for each scenario, the concentration at the local center is almost homogeneous. It decreases with time. This indicates that the ventilation progressively removes the contaminant $\left(\mathrm{CO}_{2}\right)$. Also, we observe that, for a given time, the concentration is almost constant regardless of the level of sampling. Figure 8 depicts the time evolution of the effectiveness $\left(\varepsilon_{c}\right)$ and the index of indoor air quality $\left(I_{\mathrm{IAQ}}\right)$ of the four scenarios, namely a, b, c and d. As we can see, the effectiveness of scenario $\mathrm{b}$ is low $\left(\varepsilon_{c} \approx 0.8\right)$. As for the scenarios a and $\mathrm{c}$, they provide a more or less high efficiency $\left(\varepsilon_{c} \approx 0.9\right)$.

This is the scenario $d$ that provides better efficiency $\varepsilon_{c} \approx 1$. This indicates that a such scenario removes enough the $\mathrm{CO}_{2}$. With regard to the index of indoor air quality, we get a good air quality $\left(I_{\mathrm{IAQ}}<1\right.$ after $40 \mathrm{~min}$ on average for the four scenarios. However, the scenario d takes less time (33 min only) to ensure good quality of air. This period is significantly lower in comparison with the other scenarios, showing that such a scenario is more effective than others.

We note that, for the case $b$, the temporal evolution of $\varepsilon_{c}$ and $I_{\mathrm{IAQ}}$ is different from the other cases. Otherwise, these quantities exhibit significant fluctuations because of unsteady feature of the flow. Since air is blown through four jets parallel to the ceiling, large structures occur which maintain or delay the steady state of the flow.

Following these results, it is clear that the impinging jet ventilation (scenario d) provides better ventilation efficiency, which actively discharges the $\mathrm{CO}_{2}$ and ensures good air quality in an acceptable time.

\section{Conclusion}

The turbulent contaminated flow in a 3D configuration is computationally investigated. The emphasis has been on the influence of ventilation on the indoor air quality in a ventilated room filled with air- $\mathrm{CO}_{2}$. The main aim was to test different mixing and displacement ventilation strategies. Computations have been performed with Reynolds numbers between $10^{3}$ and $10^{4}$, a Prandtl number of 0.71 and a Lewis number of 1.52. In the URANS approach, the $R N G k-\varepsilon$ turbulence model is used. From the obtained results, the following conclusions can be drawn:

- According to the results of the index of indoor air quality, the four ventilation scenarios provide an index less than the unit after a time more or less acceptable (40 min). The impinging jet ventilation (scenario d) takes less time to make a concentration of 
L. Koufi et al.: Mechanics \& Industry 18, 221 (2017)

Table 3. Measurement points.

\begin{tabular}{|c|c|c|c|c|c|c|c|c|}
\hline \multirow{2}{*}{ Points } & \multicolumn{2}{|c|}{$Z=0.8 \mathrm{~m}$} & \multirow{2}{*}{ Points } & \multicolumn{2}{|c|}{$Z=1.2 \mathrm{~m}$} & \multirow{2}{*}{ Points } & \multicolumn{2}{|c|}{$Z=1.7 \mathrm{~m}$} \\
\hline & $X(\mathrm{~m})$ & $\bar{Y}(\mathrm{~m})$ & & $X(\mathrm{~m})$ & $Y(\mathrm{~m})$ & & $X(\mathrm{~m})$ & $Y(\mathrm{~m})$ \\
\hline $\mathrm{P} 2$ & 3.0 & 1.5 & M1 & 3.0 & 2.0 & $\mathrm{P} 1$ & 3.0 & 1.5 \\
\hline $\mathrm{P} 4$ & 2.0 & 1.5 & M2 & 3.0 & 1.0 & P3 & 2.0 & 1.5 \\
\hline P6 & 1.0 & 1.5 & M3 & 2.0 & 2.0 & P5 & 1.0 & 1.5 \\
\hline P13 & 3.0 & 2.0 & M4 & 2.0 & 1.0 & P7 & 3.0 & 2.0 \\
\hline P14 & 3.0 & 1.0 & M5 & 1.0 & 2.0 & P8 & 3.0 & 1.0 \\
\hline P15 & 2.0 & 2.0 & M6 & 1.0 & 1.0 & P9 & 2.0 & 2.0 \\
\hline P16 & 2.0 & 1.0 & M7 & 3.0 & 1.5 & P10 & 1.0 & 1.0 \\
\hline P17 & 1.0 & 2.0 & M8 & 2.0 & 1.5 & P11 & 1.0 & 2.0 \\
\hline P18 & 1.0 & 1.0 & M9 & 1.0 & 1.5 & $\mathrm{P} 12$ & 1.0 & 1.0 \\
\hline
\end{tabular}
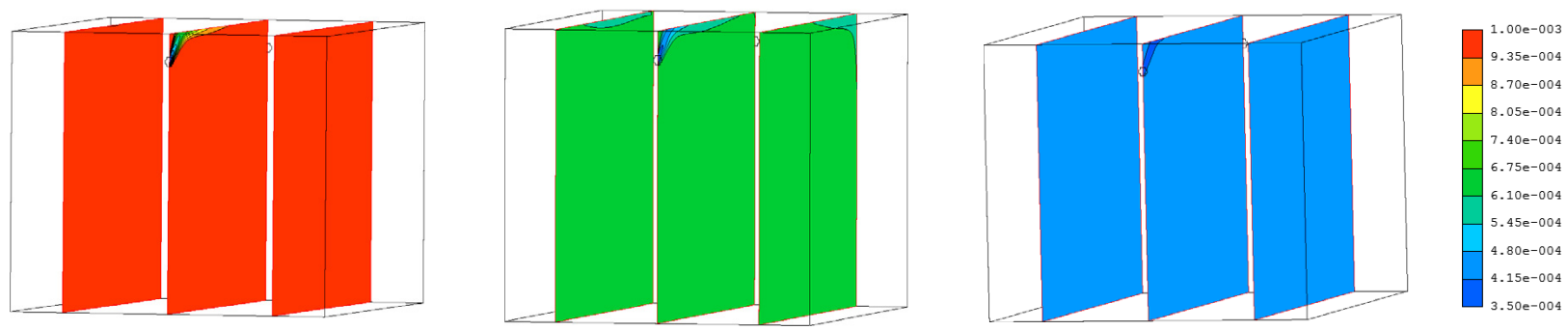

The Mixing ventilation (wall supply and extract)
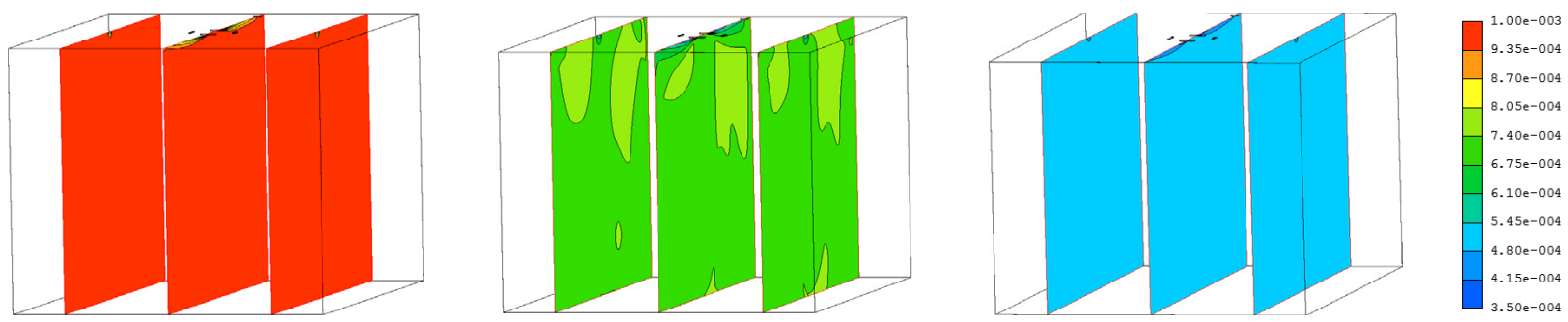

The mixing ventilation (ceiling supply and extract)
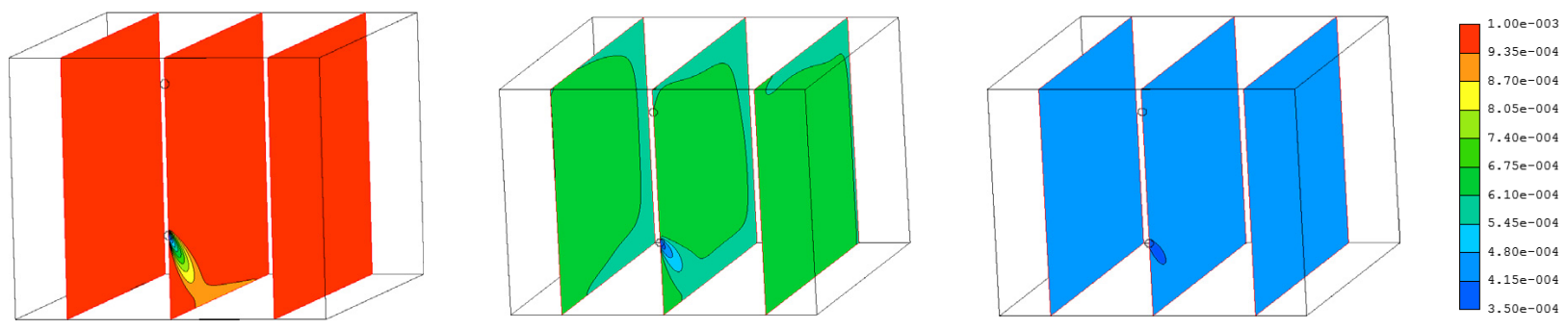

The displacement ventilation (wall supply and extract)
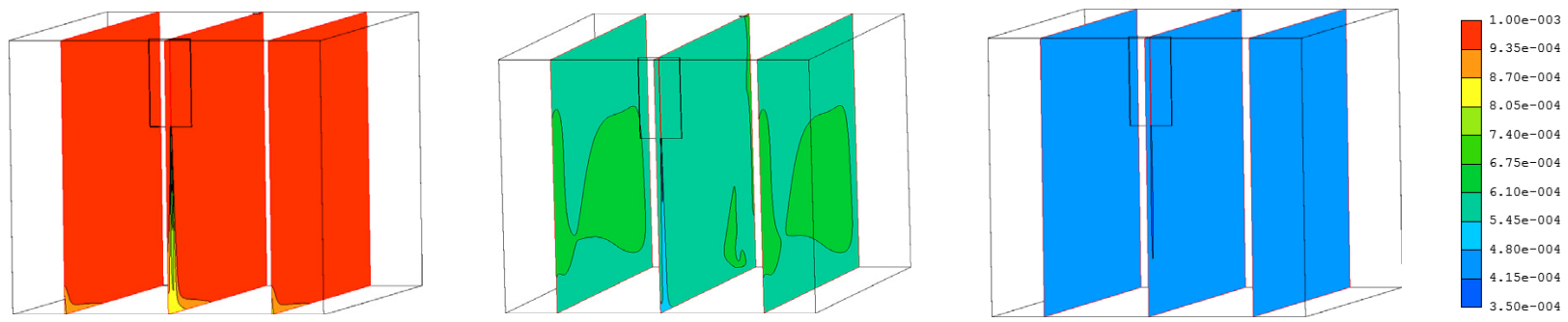

The impinging jet ventilation (ceiling supply and extract)

Fig. 6. Iso-concentrations (Kg. $\left.\mathrm{Kg}^{-1}\right): t=2000 \mathrm{~s}$ (left), $t=4000 \mathrm{~s}$ (middle), $t=6000 \mathrm{~s}$ (right). 

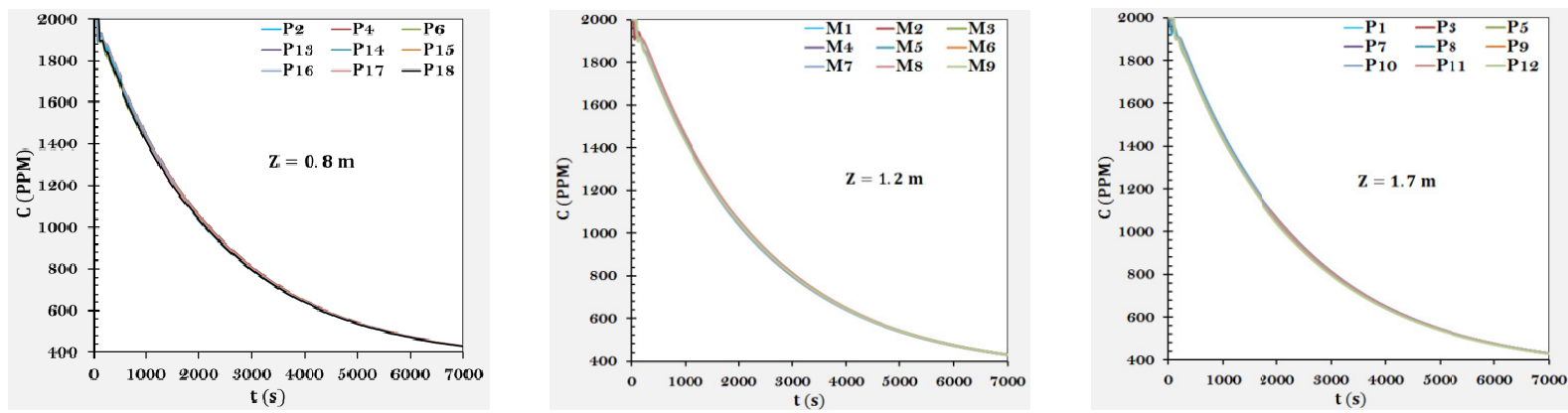

The mixing ventilation (wall supply and extract)
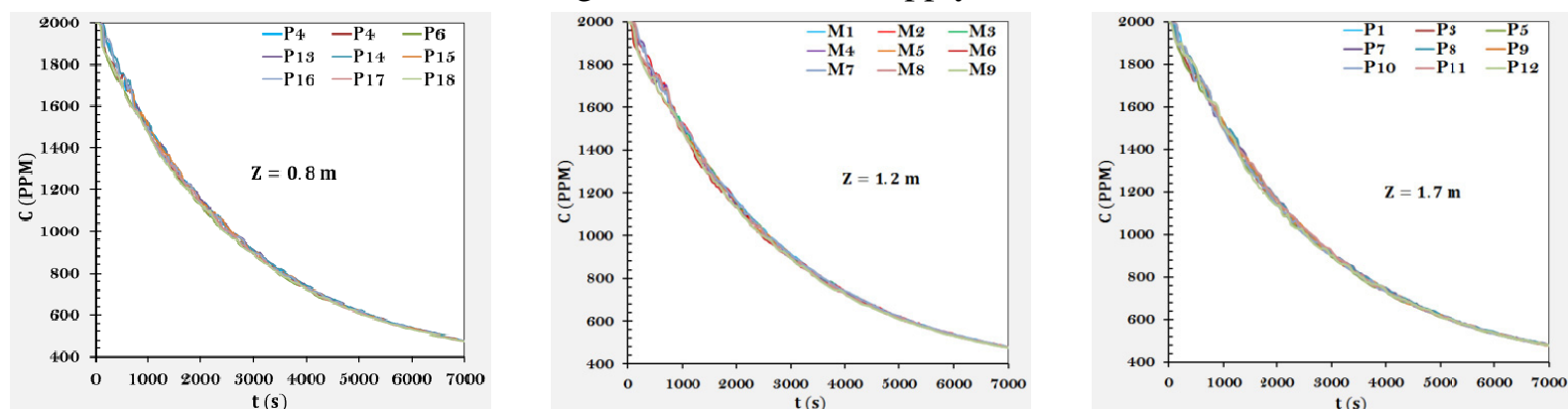

The mixing ventilation (ceiling supply and extract)
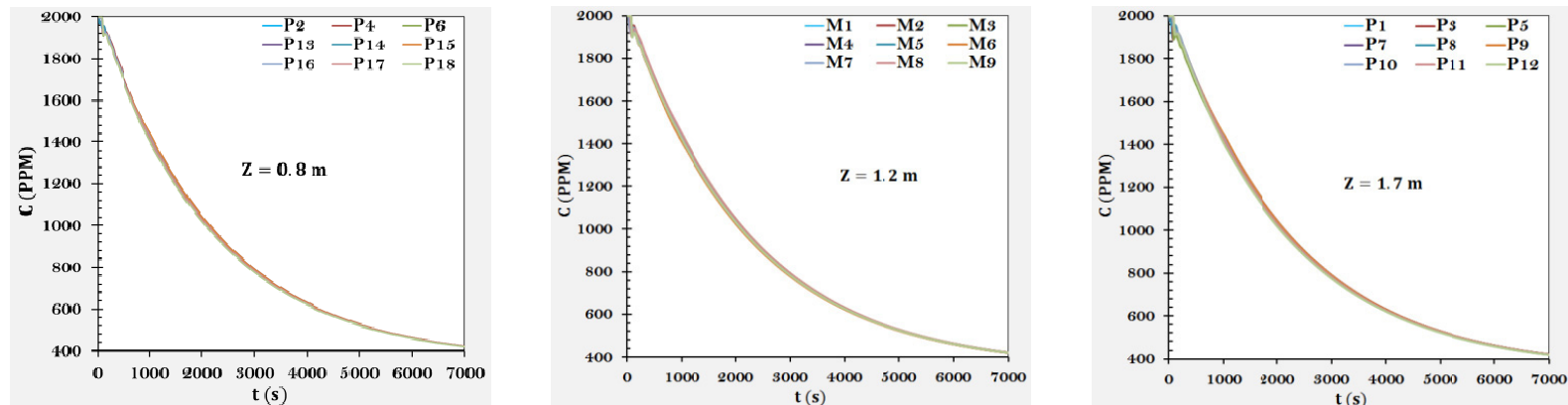

The displacement ventilation (wall supply and extract)
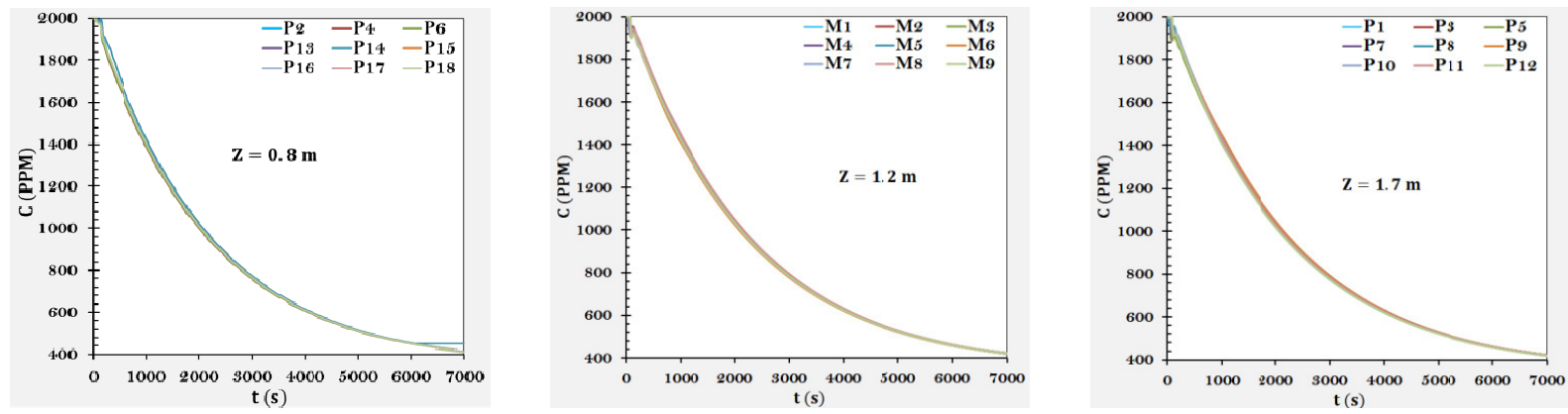

The impinging jet ventilation (ceiling supply and extract)

Fig. 7. Time evolution of the concentration (ppm): $Z=0.8 \mathrm{~m}$ (left), $Z=1.2 \mathrm{~m}$ (middle), $Z=1.7 \mathrm{~m}$ (right).

$\mathrm{CO}_{2}$ less than $10^{3} \mathrm{ppm}$ and an index of indoor air quality less than 1 , about $33 \mathrm{~min}$. Note that scenario b takes longer (12 min) than the scenario d.

- Regarding the efficiency of ventilation to remove pollutant, all scenarios provide a lower efficiency $\left(\varepsilon_{c}<1\right)$. This indicates that these scenarios do not provide effective evacuation of $\mathrm{CO}_{2}$. According to our comparison, it was found that this is the scenario d that pro- vides the better efficiency $\left(\varepsilon_{c}=0.98\right)$, the most favorable, whereas the scenario $b$ was found to be less favorable with $\varepsilon_{c}=0.8$.

- The impinging jet ventilation can ensure good air quality after $33 \mathrm{~min}$, and has better efficiency $\varepsilon_{c}$.

- Finally, all scenarios provide a velocity of ambient air well below $0.25 \mathrm{~ms}^{-1}$. This is in line with the recommendations of ASHRAE 62. 


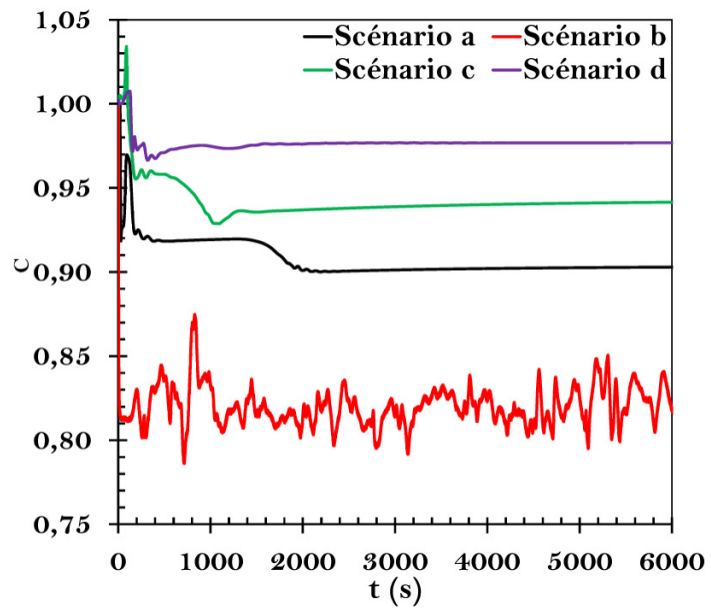

(a)

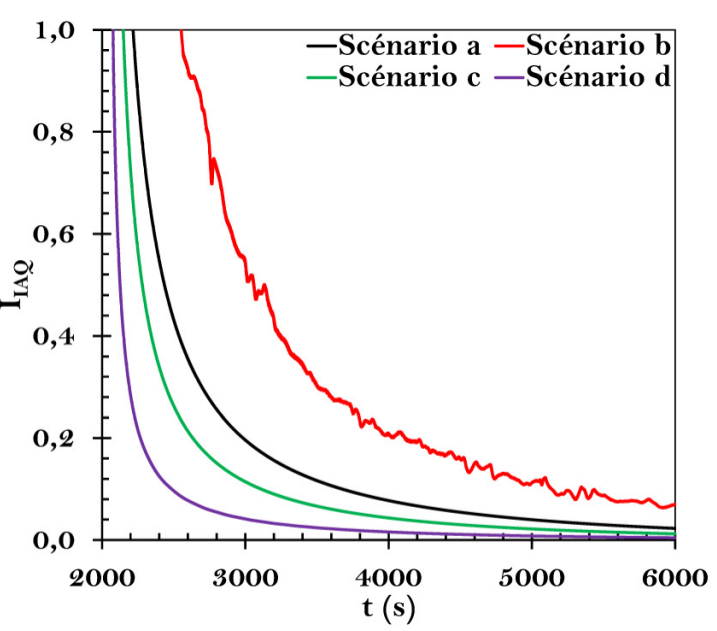

(b)

Fig. 8. Temporal evolution of $\varepsilon_{c}$ (a) and $I_{\mathrm{IAQ}}(\mathrm{b})$.

\section{References}

[1] Q.H. Deng, J. Zhou, C. Mei, Y.-M. Shen, Fluid, heat and contaminant transport structures of laminar doublediffusive mixed convection in a two-dimensional ventilated enclosure, Int. J. Heat Mass Transf. 47 (2004) 52575269

[2] H.B. Awbi, Ventilation of Buildings, 2nd ed. London; New York: Routledge, 2003

[3] K.C. Chung, S.-P. Hsu, Effect of ventilation pattern on room air and contaminant distribution, Build. Environ. 36 (2001) 989-998

[4] E. Bjørn, P.V. Nielsen, Dispersal of exhaled air and personal exposure in displacement ventilated rooms, Indoor Air 12 (2002) 147-164

[5] J. Moureh, D. Flick, Airflow characteristics within a slotventilated enclosure, Int. J. Heat Fluid Flow 26 (2005) $12-24$

[6] Z.F. Tian, J.Y. Tu, G.H. Yeoh, R.K.K. Yuen, On the numerical study of contaminant particle concentration in indoor airflow, Build. Environ. 41 (2006) 1504-1514

[7] J.D. Posner, C.R. Buchanan, D. Dunn-Rankin, Measurement and prediction of indoor air flow in a model room, Energy Build. 35 (2003) 515-526

[8] K. Niachou, S. Hassid, M. Santamouris, I. Livada, Experimental performance investigation of natural, mechanical and hybrid ventilation in urban environment, Build. Environ. 43 (2008) 1373-1382

[9] D. Liu, F.-Y. Zhao, G.-F. Tang, Numerical analysis of two contaminants removal from a three-dimensional cavity, Int. J. Heat Mass Transf. 51 (2008) 378-382

[10] Y.C. Tung, Y.-C. Shih, S.-C. Hu, Y.-L. Chang, Experimental performance investigation of ventilation schemes in a private bathroom, Build. Environ. 45 (2010) $243-251$
[11] D. Liu, F.-Y. Zhao, H.Q. Wang, E. Rank, Turbulent transport of airborne pollutants in a residential room with a novel air conditioning unit, Int. J. Refrig. 35 (2012) $1455-1472$

[12] A. Jurelionis, L. Gagyte, T. Prasauskas, D. Ciuzas, E. Krugly, L. Šeduikyte, D. Martuzevicius, The impact of the air distribution method in ventilated rooms on the aerosol particle dispersion and removal: The experimental approach, Energy Build. 86 (2015) 305-313

[13] N.A. Rodríguez, J.F. Hinojosa, J. Xamán, Comparative study between experimental data and numerical results of turbulent mixed convection in a ventilated cavity, J. Heat Transf. 137 (2015) 054501-054501

[14] V. Yakhot, S.A. Orszag, S. Thangam, T.B. Gatski, C.G. Speziale, Development of turbulence models for shear flows by a double expansion technique, Phys. Fluid A 4 (1992) 1510-1520

[15] R.A.W.M. Henkes, F.F. Van Der Vlugt, C.J. Hoogendoorn, Natural-convection flow in a square cavity calculated with low-Reynolds-number turbulence models, Int. J. Heat Mass Transf. 34 (1991) 377-388

[16] G.D.R.J.P. van Doormaal, Enhancements of the SIMPLE Method for Predicting Incompressible Fluid Flows, Numer. Heat Transf. 7 (1984) 147-163

[17] C. Béghein, F. Haghighat, F. Allard, Numerical study of double-diffusive natural convection in a square cavity, Int. J. Heat Mass Transf. 35 (1992) 833-846

[18] J. Xamán, A. Ortiz, G. Álvarez, Y. Chávez, Effect of a contaminant source $\left(\mathrm{CO}_{2}\right)$ on the air quality in a ventilated room, Energy 36 (2011) 3302-3318 